\title{
GOBIERNO CORPORATIVO EN EL SISTEMA FINANCIERO
}

Daniel Echaiz Moreno ${ }^{1}$

El 23 de enero del 2017 se publicó en el Diario Oficial El Peruano la Resolución SBS N 272-2017 mediante la cual se aprueba el Reglamento de Gobierno Corporativo y de la Gestión Integral de Riesgos (en adelante: “el nuevo Reglamento"), el mismo que entrará en vigencia el 1 de abril del 2018 y sustituye al Reglamento de la Gestión Integral de Riesgos, aprobado mediante Resolución SBS N ${ }^{\circ}$ 37-2008 (en adelante: "el anterior Reglamento), así como a las Circulares N B-1940-93, N" S-547-93, N ${ }^{\circ}$ F-283-93, N M-282-93, N CM-134-93, N EAF-137-93 y N CR-020-93.

El nuevo Reglamento persigue fundamentalmente tres objetivos: (i) modificar la normativa vigente para fomentar una mejor gestión de riesgos y gobierno corporativo en las empresas supervisadas por la Superintendencia de Banca, Seguros y Administradoras Privadas de Fondos de Pensiones (en adelante: SBS); (ii) desarrollar y establecer criterios relacionados al gobierno corporativo, como aquellos referidos al director independiente, los comités de directorio, los sistema de remuneraciones, la conducta de mercado y la gestión de conflictos de intereses; y (iii) revisar aspectos relacionados a la gestión integral de riesgos, tales como la función de cumplimiento normativo, a fin de fortalecer el desempeño y responsabilidad de las empresas. Un significativo impulso a esta materia se dio a partir de la dación de la Resolución SBS № 6422-2015 que reguló la designación de directores independientes por parte de las Administradoras Privadas de Fondos de Pensiones².

Si comparamos el nuevo Reglamento con el antiguo Reglamento en cuanto a estructura temática encontramos diferencias que abonan a favor de una mejor y más completa regulación normativa, como se aprecia a continuación:

\begin{tabular}{|l|l|}
\hline \multicolumn{2}{|c|}{ Antiguo Reglamento } \\
\hline Capítulo I & Disposiciones generales \\
\hline Capítulo II & Gestión integral de riesgos \\
\hline Capítulo III & El directorio y la gerencia \\
\hline Capítulo IV & Los comités del directorio \\
\hline Sub-Capítulo I & Comité de riesgos \\
\hline Sub-Capítulo II & Comité de auditoría \\
\hline Capítulo V & Unidad de riesgos \\
\hline Capítulo VI & Subcontratación \\
\hline Capítulo VII & Rol de la auditoría interna y externa \\
\hline Disposiciones finales y transitorias \\
\hline
\end{tabular}

Socio fundador de Echaiz Abogados y Presidente de la Comisión Consultiva de Derecho Financiero y Bancario del Ilustre Colegio de Abogados de Lima. Web: www.echaiz.com.

2 El autor de este artículo fue asesor temático de la tesis "El rol del directorio según las prácticas del buen gobierno corporativo” de Carmela Zevallos Cabanillas (Lima, Facultad de Derecho de la Universidad de Lima, 2010, 294 ps.). 


\begin{tabular}{|l|l|}
\hline \multicolumn{2}{|c|}{ Nuevo Reglamento } \\
\hline Título I & Disposiciones generales \\
\hline Título II & Gobierno corporativo \\
\hline Capítulo I & Aspectos generales \\
\hline Capítulo II & Órganos de gobierno de la empresa \\
\hline Sub-Capítulo I & Directorio \\
\hline Sub-Capítulo II & Comités del directorio \\
\hline Sub-Capítulo III & Gerencia \\
\hline Capítulo III & Conflictos de intereses y prácticas cuestionables \\
\hline Capítulo IV & Sistema de remuneraciones \\
\hline Título III & Gestión integral de riesgos \\
\hline Capítulo I & Aspectos generales \\
\hline Capítulo II & Unidad de riesgos \\
\hline Capítulo III & Cumplimiento normativo \\
\hline Capítulo IV & Subcontratación \\
\hline Disposiciones finales y complementarias \\
\hline
\end{tabular}

El nuevo Reglamento incluye un prolijo glosario (artículo 2) que, a diferencia del antiguo Reglamento, añade los conceptos de beneficiario final, capacidad de riesgo, cláusulas de blindaje, conducta de mercado, conflicto de intereses, gobierno corporativo, hechos significativos, límites de riesgo, nuevo producto, operaciones con partes vinculadas, principales funcionarios, productos, remuneración, remuneración fija, remuneración variable, sistema de apetito por el riesgo y sistema de remuneraciones; y elimina los conceptos de impacto, proba- bilidad, tolerancia al riesgo, y política y procedimientos de cumplimiento normativo.

El gobierno corporativo es el eje fundamental para la gestión integral de riesgos, guiando el accionar de los órganos de gobierno de la empresa, especificando la distribución de los derechos y responsabilidades entre los diferentes órganos de gobierno y grupos de interés (stakeholders) y proveyendo la estructura a través de la cual se establecen los objetivos de la empresa, los medios para alcanzar estos objetivos y la forma de hacerles seguimiento (artículo 3). Para ello las empresas deben contar con un Código de Ética y Conducta, un Reglamento de Directorio, un Reglamento de Comités y un Libro de Acuerdos de Comités; el directorio debe estar compuesto por un número de miembros que posibilite la conformación de los comités de directorio (artículo 4) y contar, al menos, con un director independiente en caso tengan cinco o menos directores, o con dos directores independientes en caso tengan seis directores o más (artículo 6); deben crearse cuando me- 
nos el comité de riesgos (artículos 11 y 12), el comité de auditoría (artículos 13 y 14) y el comité de remuneraciones (artículos 15 y 16); y la gerencia es responsable por asegurar que las actividades de la empresa sean consistentes con la estrategia del negocio, el sistema de apetito por el riesgo, la cultura y valores corporativos, la adecuada conducta de mercado y las políticas aprobadas por el directorio (artículo 17). Asimismo, es menester identificar los potenciales conflictos de interés (artículo 18) y las prácticas no autorizadas, ilícitas, fraudulentas y otras cuestionables (artículo 19).
En cuanto a la gestión integral de riesgos en específico (artículo 23), el nuevo Reglamento considera los siete tipos de riesgo ya contemplados en el antiguo Reglamento (riesgo de crédito, riesgo de liquidez, riesgo de mercado, riesgo de reputación, riesgo técnico, riesgo estratégico y riesgo operacional), agregando dos nuevos tipos de riesgos (riesgo de lavado de activos y del financiamiento del terrorismo y riesgo de reaseguro). Cuando el nuevo Reglamento se refiere al oficial de cumplimiento normativo a nivel corporativo ahora especifica que es designado por las empresas que formen parte de un grupo económico (artículo 33) y prevé que cada una de dichas empresas designe un coordinador corporativo en materia de cumplimiento normativo (artículo 34). También se contempla la posibilidad que un comité corporativo de la casa matriz realice funciones de alguno de los comités del directorio, para lo cual se requiere autorización expresa de la SBS (tercera disposición final y complementaria). Finalmente, el nuevo Reglamento dispone que en un plazo máximo de 120 días contados a partir del 1 de abril del 2018, las empresas deben remitir a la SBS un plan de adecuación respecto de todas sus disposiciones (artículo quinto de la Resolución SBS N²722017). 